Int. J. Electrochem. Sci., 15 (2020) $1881-1892$

\title{
Effect of Sintering Conditions on Electrochemical Properties of $\mathrm{LiNi}_{0.8} \mathrm{Co}_{0.1} \mathrm{Mn}_{0.1} \mathrm{O}_{2}$ as Cathode Material
}

\author{
Jing $\mathrm{Li}^{1}$, Maolin Zhang ${ }^{1, *}$, Dongyan Zhang ${ }^{1}$, Yangxi Yan ${ }^{1}$, Zhimin $\mathrm{Li}^{1}$, Zhiqiang $\mathrm{Nie}^{2, *}$ \\ ${ }^{1}$ School of Advanced Materials and Nanotechnology, Xidian University, Xi'an, 710071, China \\ ${ }^{2}$ Xi'an Institute of Optics and Precision Mechanics, Chinese Academy of Sciences, Xi'an, 710119, \\ China \\ *E-mail: mlzhang@xidian.edu.cn, niezq@opt.ac.cn
}

doi: $10.20964 / 2020.03 .63$

Received: 9 November 2019 / Accepted: 7 January 2020 / Published: 10 February 2020

\begin{abstract}
Many works of literature have reported the drastic effects of synthesis methods on the electrochemical performances of Ni-rich cathode materials $\mathrm{LiNi}_{0.8} \mathrm{Co}_{0.1} \mathrm{Mn}_{0.1} \mathrm{O}_{2}(\mathrm{NCM} 811)$. In this research, a two-step sol-gel method was successfully employed to synthesize pure NCM811 and the process of preparation is discussed in detail. The electrochemical properties depending on the structures and morphologies were verified by the multichannel galvanostatic system, EIS, XRD, and SEM. The results clarified that when the precursor was sintered at $750{ }^{\circ} \mathrm{C}$ for $15 \mathrm{~h}$, the sample exhibited dominant electrochemical properties with initial discharge capacities of 230.8 and $176.3 \mathrm{mAh} / \mathrm{g}$ at 0.1 and $1 \mathrm{C}$, respectively. Moreover, the capacity retention rate is as high as $79 \%$ after 100 cycles at $1 \mathrm{C}$. These excellent electrochemical properties were considered to be arriving from the well-developed layered structure and low charge transfer resistance.
\end{abstract}

Keywords: Cathode materials; $\mathrm{LiNi}_{0.8} \mathrm{Co}_{0.1} \mathrm{Mn}_{0.1} \mathrm{O}_{2}$ (NCM811); Electrochemical properties; Sol-gel method

\section{$\underline{\text { FULL TEXT }}$}

(C) 2020 The Authors. Published by ESG (www.electrochemsci.org). This article is an open access article distributed under the terms and conditions of the Creative Commons Attribution license (http://creativecommons.org/licenses/by/4.0/). 